\title{
Lateral Resistance of CLT Wall Panels Composed of Square Timber Larch Core and Plywood Cross Bands ${ }^{1}$
}

\author{
Sang Sik JANG $\mathbb{D}^{2, \dagger} \cdot$ Hyoung Woo $\mathrm{LEE}^{2}$
}

\begin{abstract}
Thinned, small larch logs have small diameters and no value-added final use, except as wood chips, pallets, or fuel wood, which are products with very low economic value; however, their mechanical strength is suitable for structural applications. In this study, small larch logs were sawed, dried, and cut into square timbers (with a $90 \mathrm{~mm} \times 90 \mathrm{~mm}$ cross section) that were laterally glued to form core panels used to manufacture cross-laminated timber (CLT) wall panels. The surface and back of these core panels were covered with 12-mm-thick structural plywood panels, used as cross bands to obtain three-ply CLT wall panels. This attachment procedure was conducted in two different ways: gluing and pressing (CGCLT) or gluing and nailing (NGCLT). The size of the as-manufactured CLT panels was 1,220 $\mathrm{mm} \times 2,440 \mathrm{~mm}$, the same as that of the plywood panels. The final wall panels were tested under lateral shear force in accordance with KS F 2154. As the lateral load resistance test required 2,440 mm $\times 2,440$ mm specimens, two CLT wall panels had to be attached in parallel. In addition, the final CLT panels had tongued and grooved edges to allow parallel joints between adjacent pieces. For comparison, conventional light-frame timber shear walls and midply wall systems were also tested under the same conditions. Shear walls with edge nail spacing of $150 \mathrm{~mm}$ and 100 $\mathrm{mm}$, the midply wall system, and the fabricated CGCLT and NGCLT wall panels exhibited maximum lateral resistances of $6.1 \mathrm{kN} / \mathrm{m}$ (100\%), $9.7 \mathrm{kN} / \mathrm{m}$ (158\%), $16.9 \mathrm{kN} / \mathrm{m}$ (274\%), $29.6 \mathrm{kN} / \mathrm{m}$ (482\%), and $35.8 \mathrm{kN} / \mathrm{m}$ (582\%), respectively.
\end{abstract}

Keywords: CLT wall panel, lateral resistance, small square timber, plywood cross band

\section{INTRODUCTION}

Thinned small larch logs having small diameter do not have specific value-added final use except wood chip, pallet or fuel wood which are products having very low economic value. Even though larch small logs do not have any value-added final usage at present time, their mechanical properties are strong enough to be used for structural purposes (Jang, 2012; Jang, 2015).
In the previous researches (Jang, 2012; Jang, 2015), sawn timbers produced from small larch logs were proved to be strong enough as laminations for structural glulam. In those researches, small larch logs were sawn to square timbers containing pith at centre, which were used as inner-laminations for structural glulam for bending and any laminations for structural glulam for compression. Moreover, in both cases, they showed sufficient structural performance under bending and

1 Date Received June 4, 2019, Date Accepted July 20, 2019

2 Department of Bio-based Materials, College of Agriculture \& Life Sciences, Chungnam National University, Daejeon 34134, Republic of Korea

† Corresponding author: Sang Sik JANG (e-mail: ssjang@cnu.ac.kr, ORCID: 0000-0002-3124-7044) 
compressive loads and were proved to have enough stiffness and strength to be used as structural members.

The idea of manufacturing CLT was started to consume more wood and to develop stronger wooden members for high-rise buildings (Blass, 2004). Dujic, et al. (2006) tested CLT wall panels under actual boundary conditions and Mestek, et al. (2008) proposed the design method of CLT panels. In recent days, many researchers have concern on CLT and performed a lot of researches, and the results of their efforts was summarized as CLT Handbook for Canada (Gagnon and Pirvu, 2011) and for the U.S. (Karacabeyli and Douglas, 2013).

CLT construction has become a new trend in the world, and more and more people in Korea also have interest in CLT construction. In Korea, Song and Hong (2016) evaluated the bonding properties of CLT manufactured by larch lumber, Pang, et al. (2017) evaluated bending properties with nailed CLT members loaded perpendicular to plane, and Oh, et al. (2017) tested about the adequate end distance for single-shear screw connection in CLT. However, good quality timbers produced in Korea are so expensive that CLT manufactured by using those has economically no competitive power with other construction materials. The method of importing timbers for CLT manufacturing is not a good idea because it is still expensive compared with the imported CLT manufactured in other countries. It is also not a good idea in terms of environmental consideration because importing timber or CLT from other countries include consuming oils for transportation and producing additional $\mathrm{CO}_{2}$.

Therefore, the idea of manufacturing CLT with small square timbers and plywood, which are both relatively low price in Korea, was developed to manufacture CLT that is economically competitive with other materials. Small square timbers were already proved to have enough stiffness and strength as a structural material. Therefore, CLT panels manufactured by using small square timbers were also expected to have enough strength to be used as vertical and horizontal diaphragms. In this study, straight small larch logs were selected, sawed, dried and finished to produce square timbers with $90 \mathrm{~mm} \times 90 \mathrm{~mm}$ cross section, which were glued laterally to form core panels used to manufacture CLT wall panels. In addition, $12 \mathrm{~mm}$ thick structural plywood panels were used as cross bands to manufacture three-ply CLT wall panels by covering the surface and the back of larch square timber core panel.

\section{MATERIALS and METHODS}

\subsection{Core panel}

In this study, larch logs having age less than 18 years, diameter between $120 \mathrm{~mm} \sim 150 \mathrm{~mm}$, and straight shape were selected among the thinned small logs. They were sawed to $105 \mathrm{~mm} \times 105 \mathrm{~mm}$ square timbers by the method as shown in Fig. 1.

Sawn timbers were dried to the target moisture content of $15 \%$ by applying the following drying schedule to minimize drying defects developed during the drying process:

(1) Moisturizing for 12 hours at $96^{\circ} \mathrm{C}$

(2) High temperature drying for 36 hours at dry bulb temperature of $120^{\circ} \mathrm{C}$ and wet bulb temperature of $90^{\circ} \mathrm{C}$

(3) Medium temperature drying for 24 hours at dry bulb temperature of $100^{\circ} \mathrm{C}$ and wet bulb temperature of $70^{\circ} \mathrm{C}$

(4) Low temperature drying for 24 hours at dry bulb temperature of $80^{\circ} \mathrm{C}$ and wet bulb temperature of $60^{\circ} \mathrm{C}$

(5) Conditioning for 3 days at room temperature

The dried timbers were finished to produce small square timbers having cross section of $90 \mathrm{~mm} \times 90$ $\mathrm{mm}$. These small square timbers were visually graded 

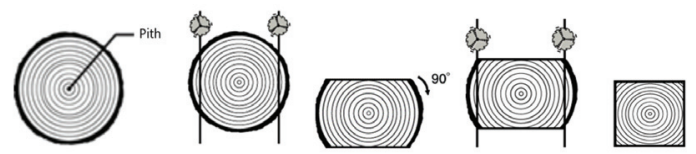

Fig. 1. Sawing method for small logs to produce small square timbers.

in accordance with the quality standard for lamination given in KS F 3021. Results of visual grading for small square timbers are No. 1(18.8\%), No. 2(37.7\%), No. $3(37.0 \%)$ and No. 4(6.5\%), among which all the small square timbers except No. 4 were used to produce core panels for CLT. Small square timbers were glued together laterally to form $1,220 \mathrm{~mm} \times 2,440 \mathrm{~mm}$ panels, which were used as cores for CLT wall panels.

\subsection{Cross band}

No. 1 grade of structural plywood conforming to KS F 3113 having size of 1,220 mm $\times 2,440 \mathrm{~mm}$, produced in Korea, were used as cross band covering the surfaces and the backs of small square timber cores to manufacture 3 ply CLT wall panels. The thickness of plywood used to manufacture CLT was $12 \mathrm{~mm}$, and their bending strength and stiffness were $25.5 \mathrm{MPa}$ and 5.5 GPa parallel to strong axis, and 19.5 $\mathrm{MPa}$ and 3.5 GPa parallel to weak axis.

\subsection{CLT wall panel specimen}

The adhesive of brand name Okong (acetylated vinyl based glue) was used to make bonding between core and cross band. When making adhesion between core and cross band, the glue spreading rate was $150 \mathrm{~g} / \mathrm{m}^{2}$. The pressure required to make a strong bonding was applied by two method. The first method was application of $1 \mathrm{MPa}$ of pressure for 2 hours, which produced the specimen named CGCLT. The second method was nailing of 8d nails with $150 \mathrm{~mm}$ spacing along the edge and $300 \mathrm{~mm}$ spacing in the field, which produced the specimen named NGCLT. In NGCLT specimen,

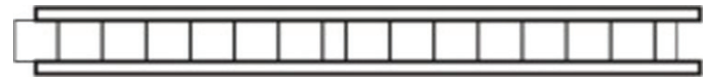

Fig. 2. CLT wall panel with T\&G edge.

the spacing between rows of nails was $400 \mathrm{~mm}$ and nails applied pressure to plywood face and small square timber core. The advantage of nailing was that it is not required to keep the pressure for two hours until the bond cures completely. Therefore, CLT products can be released right after nailing and can save time for production of CLT. CLT wall panel specimens were manufactured with one long edge of tongue and the other long edge of groove as shown in Fig. 2 so that T\&G parallel joints are possible between CLT wall panels.

Nailing patterns applied to manufacture NGCLT specimen is shown in Fig. 3, in which patterns (a) and (b) were applied to the surface plywood and the back plywood, respectively.

The CLT wall panels with T\&G edge manufactured at factory can be moved to construction site and the adjacent CLT panels can be joined together to form parallel T\&G joint as shown in Fig. 4 to make vertical diaphragm.

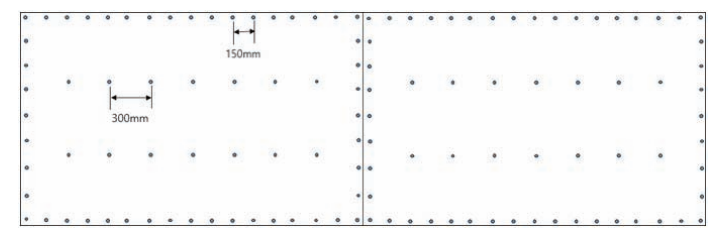

(a) Nailing at the surface plywood for NGCLT specimen

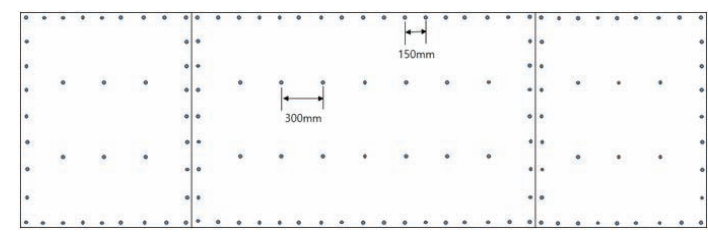

(b) Nailing at the back plywood for NGCLT specimen

Fig. 3. Nailing patterns for NGCLT specimen. 


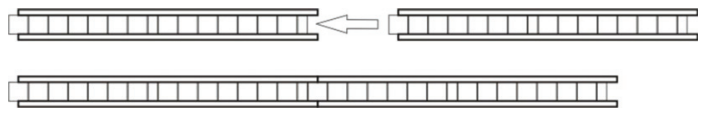

Fig. 4. Making parallel T\&G joints between the adjacent CLT wall panels.

Before making T\&G joints between two CLT wall panels, adhesives were spread thoroughly on groove part, and tongue part was pressed into the groove. To make a secure T\&G joint between CLT panels, 8d nails were used with $100 \mathrm{~mm}$ spacing along the edge on both sides.

\subsection{Shear wall SPECIMEN}

To compare the lateral resistance of CLT wall panels with three other types of well-known vertical diaphragms, specimens of conventional light-frame timber shear walls (S150 (common conventional type) and S100 (reinforced conventional type) specimens) and mid-ply shear wall system(MP specimen) were constructed. S150 specimen was constructed with $38 \mathrm{~mm}$ $\times 89 \mathrm{~mm}$ dimension lumber framing with $406 \mathrm{~mm}$ spacing, $11.1 \mathrm{~mm}$ thick OSB as sheathing, and nailing of 8d nails with $150 \mathrm{~mm}$ edge nail spacing and 300 $\mathrm{mm}$ field nail spacing. 16d nails were used for joints between framing members. S100 specimen has the same composition as S150 specimen except that nail spacing was reduced to $100 \mathrm{~mm}$ along the edge and $200 \mathrm{~mm}$ in field. MP (Mid-ply) shear wall system developed in Canada was also selected to compare their lateral resistance with CLT wall panels. MP specimen was constructed by applying the standard manufacturing method for single MP shear wall system as shown in Fig. 5.

\subsection{Testing method}

The lateral-load resistance tests were performed in accordance with KS F 2154. To investigate the lateral resistance of CLT wall panels under horizontal loads,

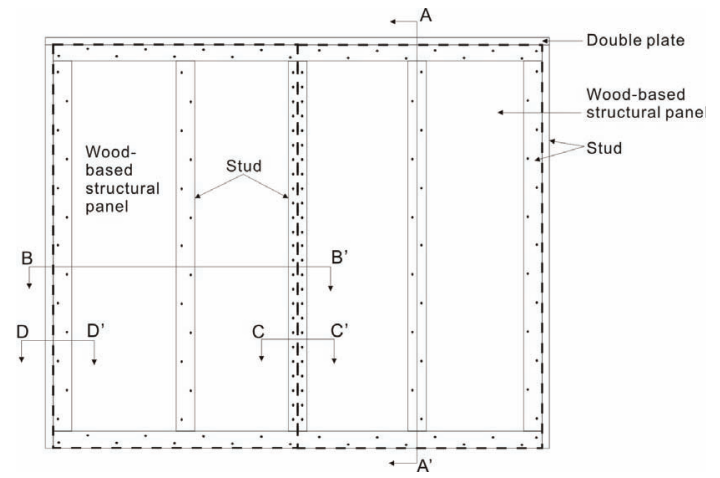

(a) MP shear wall
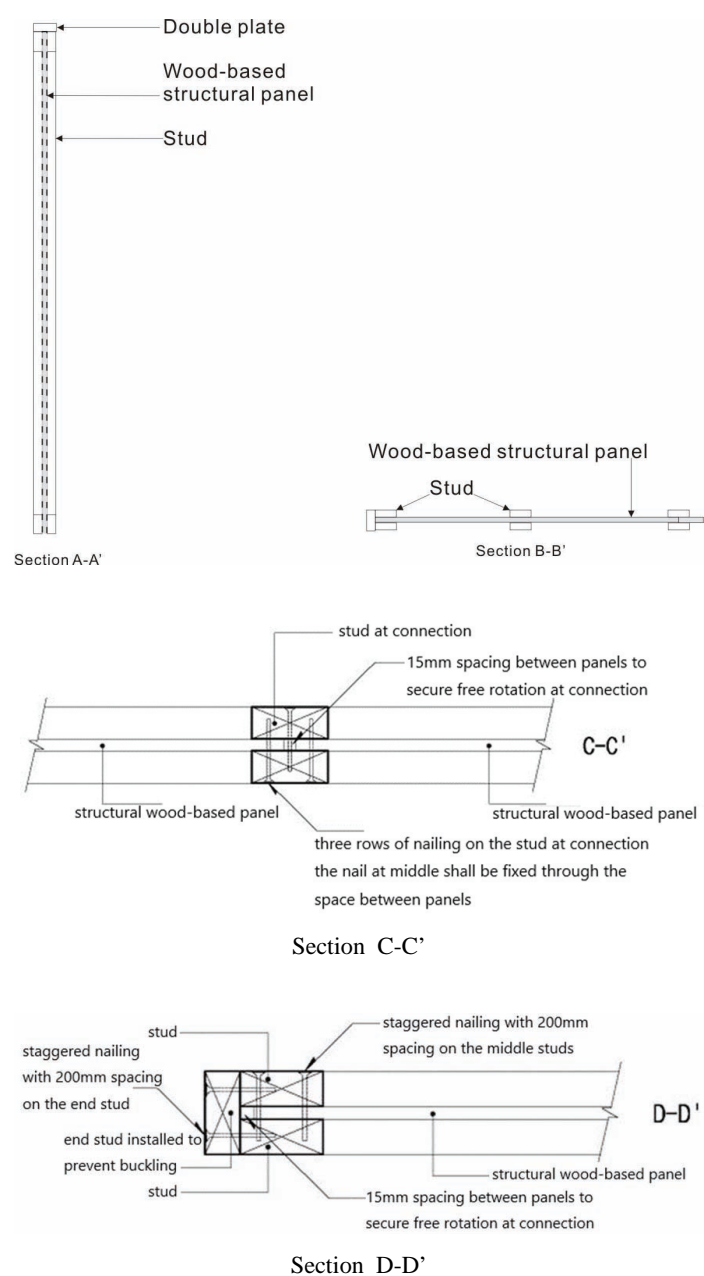

(b) Section of MP shear wall

Fig. 5. Standard single MP shear wall. 


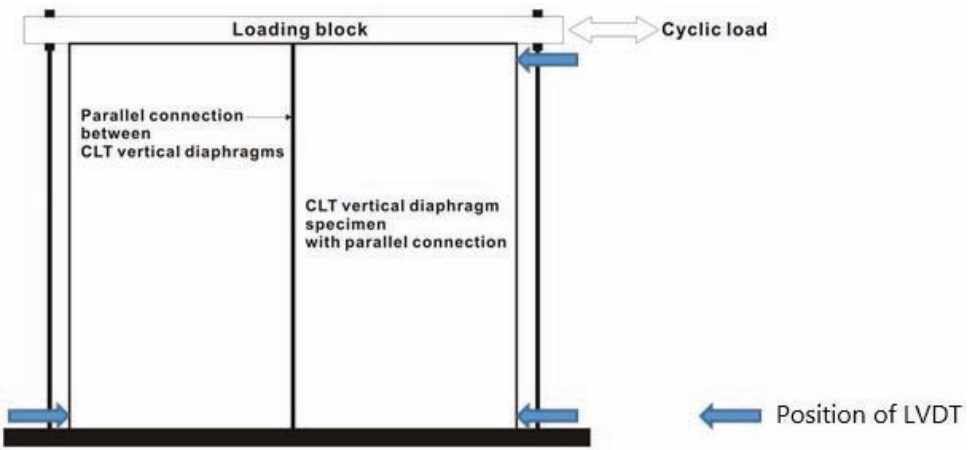

Fig. 6. Testing method for lateral-load resistance of wall panels as given in KS F 2154.

the testing method given in KS F 2154 was applied as shown in Fig. 5. During the tests, displacement was measured at three point including bottom at both ends and top right-hand side. To compare the lateral-load resistance of CLT wall panel with other types of shear walls including the conventional light framing and mid-ply shear wall, lateral load resistance tests as shown in Fig. 6 were performed with S150, S100, MP, CGCLT and NGCLT specimens. No. of replication was 3 for each specimen type. In Fig. 6, the width and height of specimen were 2,440 $\mathrm{mm} \times 2,440 \mathrm{~mm}$ and $90 \mathrm{~mm}$ $\times 90 \mathrm{~mm}$ sill plates were installed by using anchor bolts of $15 \mathrm{~mm}$ diameter with 300mm spacing. For S150 and S100 specimen, the bottom plate was fixed to the sill plate by nailing two 16d nails with $406 \mathrm{~mm}$ spacing and hold down connector was installed at both ends of the specimen. For MP and CLT specimens, $200 \mathrm{~mm} \times 200 \mathrm{~mm}$ steel plates of $6 \mathrm{~mm}$ thickness were used to connect between the specimen and the sill plate with $610 \mathrm{~mm}$ spacing at each surface. At both ends of MP and CLT specimens, two 900mm long steel straps were installed at each end instead of hold down. For steel plate connections, 10 screws of $38 \mathrm{~mm}$ length were installed at sill plate and specimen, respectively. For steel strap connections at both ends, two steels straps were inserted into the bottom of the sill plate at each end and they were bent to upright position, and 10

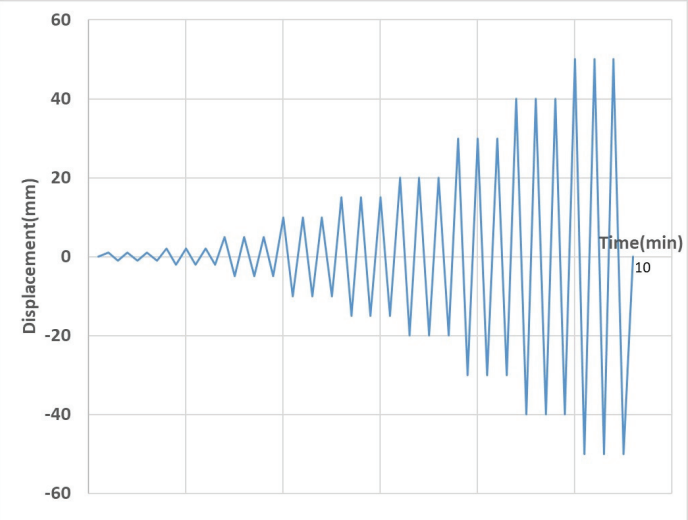

Fig. 7. Quasi-static cyclic load function applied to lateral resistance tests of CLT wall panels.

screws of $38 \mathrm{~mm}$ length were installed at one end of a steep strap, respectively.

The lateral load applied to the specimen in Fig. 6 was quasi-static cyclic load having load function as shown in Fig. 7. The load function in Fig. 7 was composed of 9 steps including $1 \mathrm{~mm}, 2 \mathrm{~mm}, 5 \mathrm{~mm}, 10$ $\mathrm{mm}, 15 \mathrm{~mm}, 20 \mathrm{~mm}, 30 \mathrm{~mm}, 40 \mathrm{~mm}$ and $50 \mathrm{~mm}$ displacement and each loading step was composed of three replications.

The ultimate shear strength and the apparent shear stiffness were calculated from the test results by using equations (1) and (2). 


$$
S_{u}=\frac{P_{u}}{b}
$$

in which, $S_{u}$ : Ultimate shear strength $(\mathrm{N} / \mathrm{m})$

$P_{u}$ : Maximum load or the load at $50 \mathrm{~mm}$ displacement $(\mathrm{N})$

$b$ : Width of the specimen (m)

$$
\mathrm{G}=\frac{P}{d} \times \frac{a}{b}
$$

in which, G: Apparent shear stiffness $(\mathrm{N} / \mathrm{mm})$

$P$ : The load equal to $1 / 3$ of the maximum load $(\mathrm{N})$

$a$ : Height of specimen $(\mathrm{mm})$

$b$ : Width of specimen $(\mathrm{mm})$

$d$ : Total displacement $(\mathrm{mm})$

\section{RESULTS and DISCUSSION}

\subsection{Lateral resistance}

The load-displacement diagrams obtained from the lateral-load resistance tests are given in Fig. 8 for S150 specimen, Fig. 9 for S100 specimen, Fig. 10 for MP specimen, Fig. 11 for CGCLT specimen and Fig. 12 for NGCLT specimen.

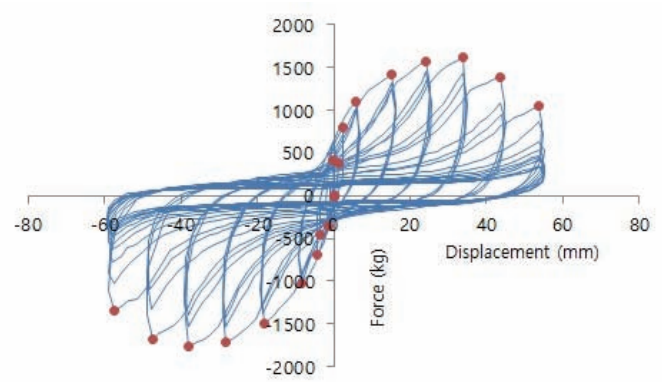

Fig. 8. Load-displacement diagram obtained from lateral-load resistance test for S150 specimen.

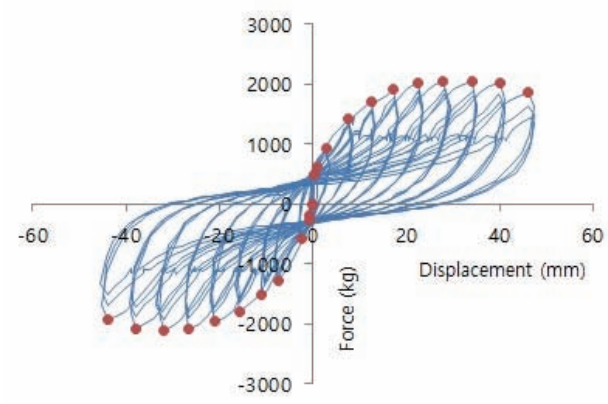

Fig. 9. Load-displacement diagram obtained from lateral-load resistance test for S100 specimen.

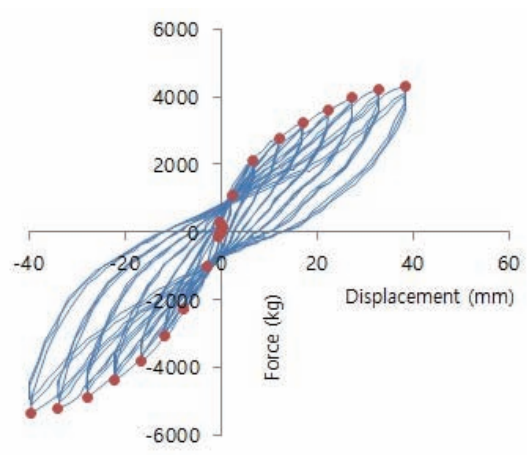

Fig. 10. Load-displacement diagram obtained from lateral-load resistance test for MP specimen.

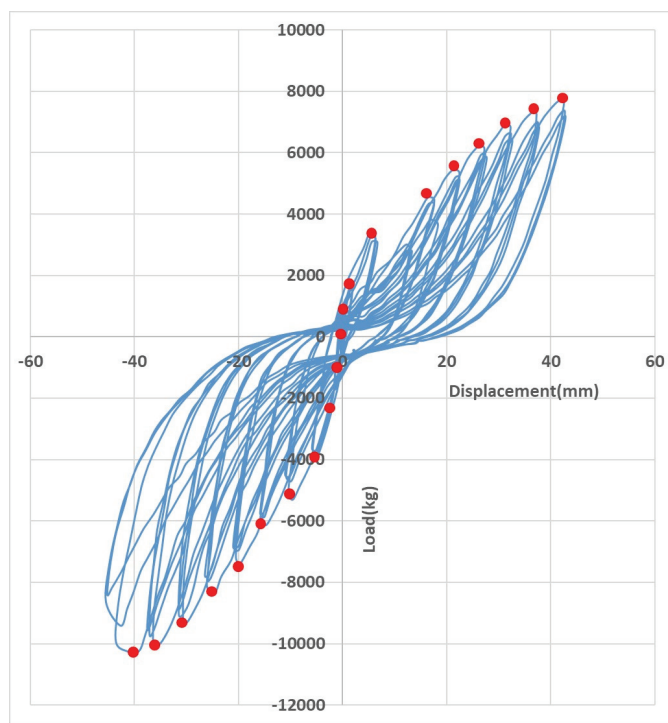

Fig. 11. Load-displacement diagram obtained from lateral-load resistance test for CGCLT specimen.

The load-displacement diagrams for S150, MP, CGCLT and NGCLT specimens are drawn together as shown in Fig. 13. From Fig. 13, it can say that NGCLT wall panel is strongest among the wall panels tested in this study, and S150 specimen showed the weakest shear strength. When comparing Fig. 8 with Fig. 9 and Fig. 10, it is known that S100 is stronger than S150 as a shear wall and MP is stronger than S100. After the tests, CGCLT and NGCLT specimens showed no damage in panel itself and failure was concentrated 


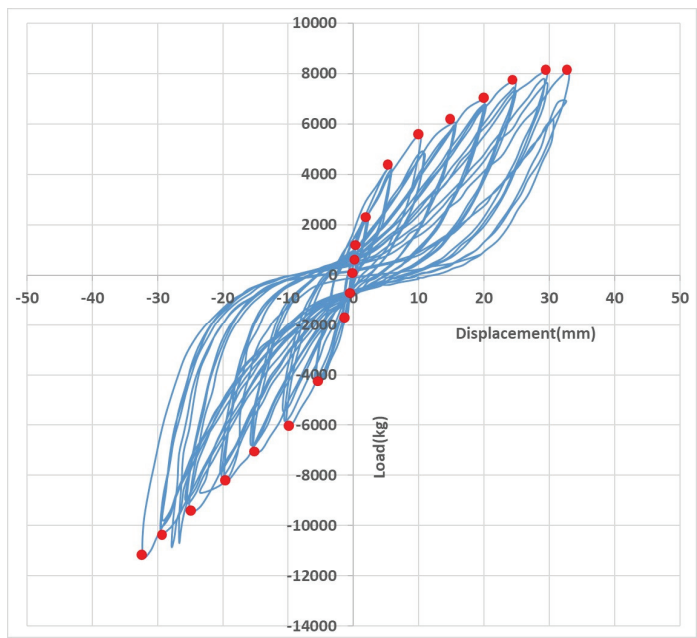

Fig. 12. Load-displacement diagram obtained from lateral-load resistance test for NGCLT specimen.

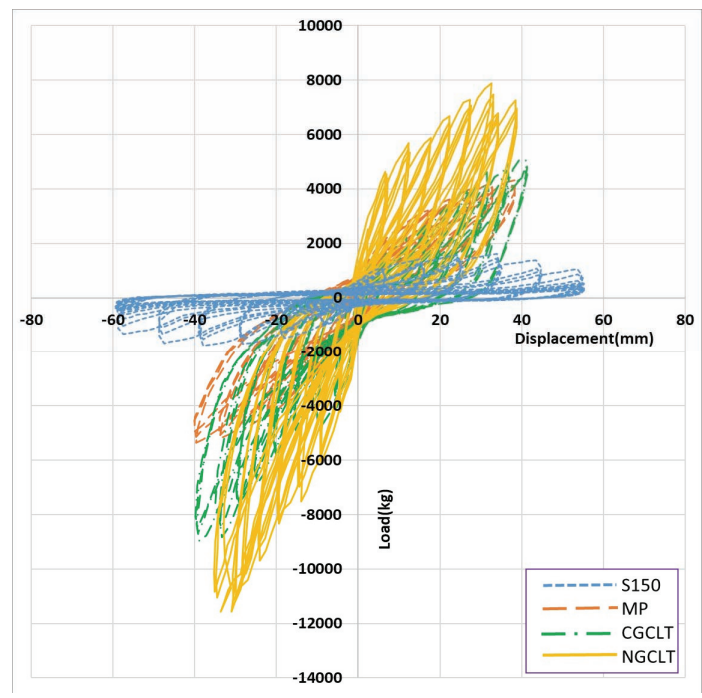

Fig. 13. Comparison of the load-displacement diagrams for S150, MP, CGCLT and NGCLT specimens.

in the lower connection between CLT panel and sill plate, which was the same as the European and North American experiences that the nonlinear behaviour and the potential damage were localized to the hold-down and bracket connection areas only (Gagnon and Pirvu, 2011; Karacabeyli and Douglas, 2013).

\subsection{Envelop curve}

The load-displacement diagram for S150 specimen given in Fig. 8 can be expressed as an envelop curve as shown in Fig. 14.

In Fig. 14, the initial slope of the envelop curve under $5,000 \mathrm{~kg}$ corresponds to the shear stiffness and the maximum load correspond to the shear strength. The envelop curve for MP specimen is given in Fig. 15 , which shows higher stiffness and strength compared to those of S150 specimen given in Fig. 14.

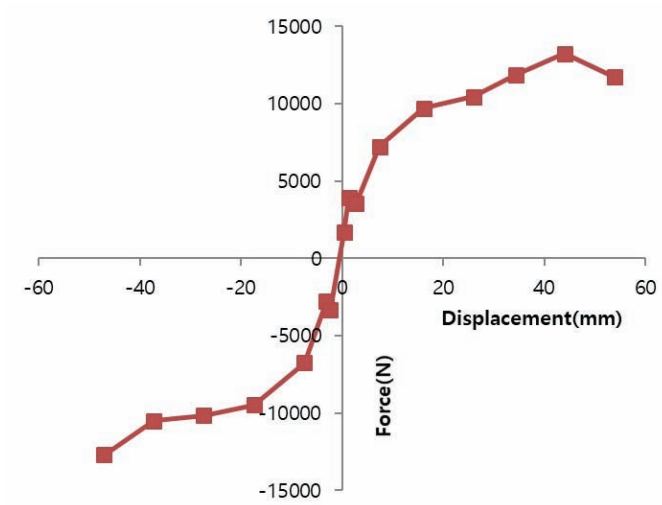

Fig. 14. Envelop curve obtained from the loaddisplacement diagram for S150 specimen.

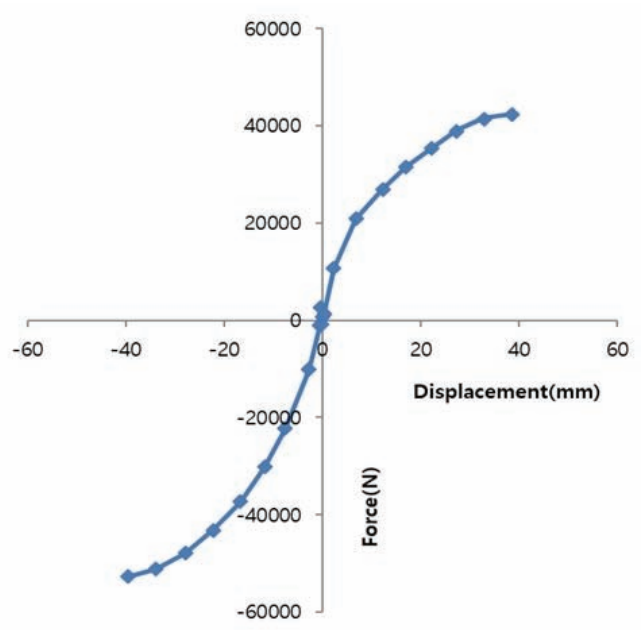

Fig. 15. Envelop curve obtained from the loaddisplacement diagram for MP specimen. 


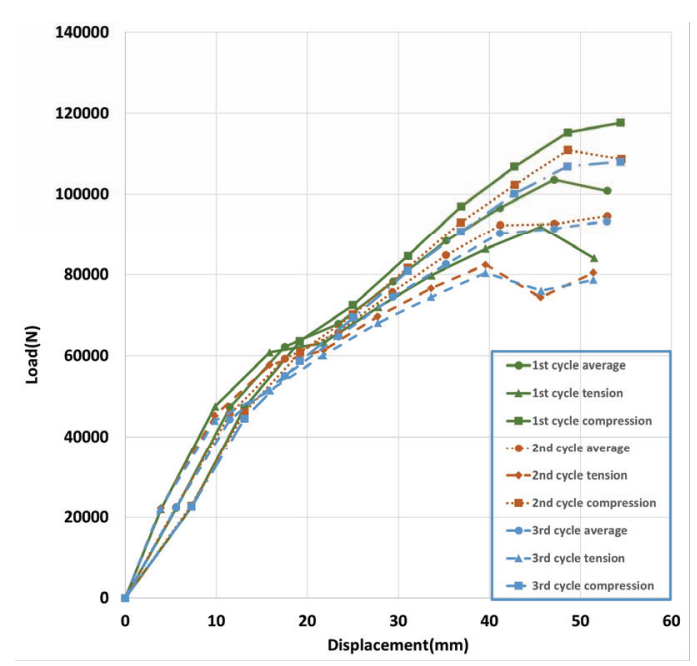

Fig. 16. Envelop curve of compression part, tension part and their average for each of three loading steps for NGCLT specimen.

The envelop curve as shown in Fig. 14 and 15 can be drawn for each of the first, second and third cycle because each step of load function is composed of three cycles. The envelop curve for the first load cycle is called as the initial envelop curve and that for the third load cycle is called as the stabilized envelop curve. The envelop curve under the second load cycle usually represent the characteristics of the material under lateral loads.

Fig. 16 shows all the envelop curves for NGCLT specimen including compression part, tension part and their average for each of three cycles.

As shown in Fig. 16, the slope of the envelop curve is decreasing as the number of cycles increase. The envelop curves for all the tested specimens, which were similar to Fig. 14 and 15, were drawn to find shear stiffness and strength.

\subsection{Shear stiffness and strength}

The apparent shear stiffness and the ultimate shear strength values for the specimens tested in this study are given in Table 1. As shown in Table 1, NGCLT
Table 1. Results of lateral-load resistance tests for wall panel specimens

\begin{tabular}{lcccc}
\hline \multirow{2}{*}{ Kind } & \multicolumn{2}{c}{ Shear strength } & \multicolumn{2}{c}{ Shear stiffness } \\
\cline { 2 - 5 } & $(\mathrm{kN} / \mathrm{m})$ & $\%$ & $(\mathrm{~N} / \mathrm{mm})$ & $\%$ \\
\hline \hline S150 & 6.15 & 100 & 122 & 100 \\
S100 & 9.71 & 158 & 192 & 157 \\
MP & 16.86 & 274 & 559 & 458 \\
CGCLT & 29.63 & 482 & 455 & 373 \\
NGCLT & 35.82 & 582 & 547 & 448 \\
\hline
\end{tabular}

specimen showed the highest shear strength(lateral-load resistance), CGCLT specimen was the second highest, MP specimen was the third, S100 specimen was the fourth, and S150 specimen showed the weakest lateralload resistance. The shear strength of the conventional light-frame wood shear wall increased about 50\% when the space between nails decreased from $150 \mathrm{~mm}$ (S150) to $100 \mathrm{~mm}$ (S100) along the edge of panels. MP shear wall showed 2.7 times higher shear strength than S150 shear wall. CGCLT and NGCLT specimens showed 4.8 and 5.8 times higher shear strengths than that of S150 shear wall, respectively.

The apparent shear stiffness for CGCLT and NGCLT specimens were $455 \mathrm{~N} / \mathrm{mm}$ and $547 \mathrm{~N} / \mathrm{mm}$, and the ultimate shear strength for CGCLT and NGCLT specimens were $29.63 \mathrm{kN} / \mathrm{m}$ and $35.82 \mathrm{kN} / \mathrm{m}$, respectively. NGCLT showed higher shear stiffness and strength than CGCLT, which shows the effect of nails resisting the movement caused by the applied lateral loads. Therefore, it can say that nailing, when manufacturing CLT with square timber core and plywood cross bands, has effect of increasing the stiffness and strength of CLT as well as the advantage of saving time for manufacturing CLT products.

\section{CONCLUSION}

In this study, larch small square timbers were edge glued together to form core panel for CLT manu- 
Lateral Resistance of CLT Wall Panels Composed of Square Timber Larch Core and Plywood Cross Bands

facturing, and $12 \mathrm{~mm}$ thick plywood panels were used as cross bands by covering the surface and the back of core panel. The plywood was attached to the surface and the back by two method including gluing and pressing, and gluing and nailing. In addition to CLT wall panels, conventional light frame wood shear walls and MP shear wall specimens were constructed to compare their lateral-load resistance. The conventional light frame wood shear wall specimen include two types such as nailing space of $150 \mathrm{~mm}$ and $100 \mathrm{~mm}$ along the edge of sheathing. In addition, another type of specimen was mid-ply shear wall in which wood-based panels are inserted in between two studs assembled face-to-face while the sheathing is attached on top of stud framing in the conventional shear wall specimen. All the wall panel specimens were tested under lateral loads in accordance with KS F 2154.

The lateral loads were applied as a quasi-static cyclic load function that is composed of nine loading steps in which each loading step is composed of three cyclic loads. As results of lateral-load resistance tests, loaddisplacement diagrams were obtained from which envelop curves were drawn. From the envelop curves, the apparent shear stiffness and the ultimate shear strength were calculated for each specimen type. Among the five specimen types, CLT specimens showed very high stiffness and strength compared to other types of specimens. In CLT specimens, NGCLT showed higher strength than CGCLT which state that nailing on plywood to attach plywood has effect of increasing the strength and stiffness. When compared to the shear strength of S150 shear wall, S100, MP, CGCLT and NGCLT specimens showed 1.5, 2.7, 4.8 and 5.8 times higher strength.

\section{ACKNOWLEDGMENT}

This research was supported by Chungnam National University (2017 CNU Academic Research Fund).

\section{REFERENCES}

Blass, H.J., Fellmoser, P. 2004. Design of solid wood panels with cross layer. In: Lahti, Finland, Proceedings of the 8th World Conference on Timber Engineering (WCTE 2004) 2, pp.543-548.

Dujic, B., Aicher, S., Zarnic, R. 2006. Testing of wooden wall panels applying realistic boundary conditions. In: Portland, USA, Proceedings of the 9th World Conference on Timber Engineering (WCTE 2006) 2, pp.1186-1193.

Gagnon, S., Pirvu, C., ed. 2011. CLT Handbook, Canadian edition. FP innovations, Pubcation No. SP528E, Quebec, Canada.

Jang, S.S. 2012. Development of multi-layer glued members used for construction of Korean-style houses by utilizing thinned domestic small logs. Report submitted to Ministry for Food, Agriculture, Forestry and Fisheries, No. 11-1541000-001480-01. Jang, S.S. 2015. Improvement of structural performance of multi-layer glued members manufactured from domestic small timbers which are not used for high value-added products. Report submitted to Korea Forestry Service, No. 11-1400000-000688-01.

Karacabeyli, E., Douglas, B., ed. 2013. CLT Handbook, U.S. edition. FP innovations, Pubcation No. SP-529E. Quebec, Canada.

Korea Standard Association: Method of shear resistance test for light-frame wood shear walls. KS F 2154, 2006.

Korea Standard Association: Structural glued laminated timber. KS F 3021, 2013.

Korea Standard Association: Structural plywood. KS F 3113, 2016.

Mestek, P., Kreuzinger, H., Winter, S. 2008. Design of cross laminated timber(CLT). In: Miyazaki, Japan, Proceeding of the 10th World Conference on Timber Engineering (WCTE 2008), pp. 61.

Oh, J.K., Kim, G.C., Kim, K.M., Lee, J.J., Hong, J.P. 
2017. End distance of single-shear screw connection in cross-laminated timber. Journal of the Korean Wood Science and Technology 45(6): 746-752.

Pang, S.J., Kim, K.M., Park, S.H., Lee, S.J. 2017. Bending behavior of nailed-jointed cross-laminated timber loaded perpendicular to plane. Journal of the Korean Wood Science and Technology 45(6): 728-736.

Song, Y.J., Hong, S.I. 2016. Evaluation of bonding strength of larch cross-laminated timber. Journal of the Korean Wood Science and Technology 44(4): 607-615. 